\title{
Interacciones culturales para la puesta en valor de la arquitectura tradicional construida en tierra
}

El municipio almeriense de Oria ha acogido las dos ediciones, celebradas hasta la fecha, de las Jornadas patrimoniales sobre la arquitectura de tierra (11-13 de agosto de 2017 y 27-29 de julio de 2018). La elección de la sede respondía a la existencia de una plural arquitectura de tierra y al carácter proactivo de su población. Los resultados positivos, que constatan que la arquitectura tradicional construida en tierra se asume como un elemento identitario de los pueblos, que debe ser salvaguardado, y que representa una alternativa sostenible frente a otros tipos de técnicas y materiales, garantiza la continuidad de las jornadas patrimoniales para 2019.

Jorge Moya Muñoz | Universidad de Sevilla ${ }^{1}$

URL <http://www.iaph.es/revistaph/index.php/revistaph/issue/view/4276>

La iniciativa de las jornadas patrimoniales surge, en primer lugar, de forma teórica como trabajo académico en el desarrollo de la asignatura de Dinamización del Máster en Arquitectura y Patrimonio Histórico de la Universidad de Sevilla y del Instituto Andaluz del Patrimonio Histórico. La preocupación sobre los aspectos perceptivos de esta arquitectura es la que motiva el trabajo. La propuesta se centró en plantear mecanismos que potencialmente fueran capaces de educar la mirada hacia este patrimonio altamente desprotegido y desconsiderado.

Los cambios de forma de vida y los nuevos hábitos de consumo han llevado a la estigmatización paulatina de la arquitectura tradicional construida en tierra. Se puede considerar que la percepción social mayoritaria asume que se trata de una arquitectura desfasada, que pertenece exclusivamente al pasado y a clases o épocas de escasa prosperidad económica.

En segundo lugar, el material tierra ofrece muy poca confianza, viéndose desplazado en favor de otros materiales industrializados. A esta impresión contribuye la obsolescencia del uso primario de parte de estas construcciones, que al ser abandonadas y por lo tanto carecer de mantenimiento, se ven desprotegidas y se muestran cada vez más vulnerables a las inclemencias del tiempo. A este pensamiento hemos de añadir el desconocimiento por parte de personas técnicas o autoconstructoras, que ante la incapacidad de hacer una lectura global de estas construcciones, justifican el intervencionismo destructivo de las mismas en base a criterios cualitativos poco profesionales y menos fundamentados.

Consecuencia de esta reflexión es que resulta necesario incidir fundamentalmente en la erradicación de los estereotipos que rodean a la arquitectura tradicional construida con tierra, proponiendo un discurso objetivo en torno a sus aspectos positivos y negativos a partir de una visión holística que incorpore el discurso patrimonial. El punto de partida radica por lo tanto en el conocimiento, la aceptación y la valoración de la arquitectura tradicional construida en tierra asociada a una forma de vida o uso, que es resultado de la adaptación secular a un determinado medio físico y a unos condicionantes históricos, donde el aprovechamiento de sus recursos naturales determina sus aspectos formales y supone un rasgo identitario de un pueblo.

Con esta premisa se propuso el salto del plano académico a la intervención efectiva. La idoneidad de la aplicación en el municipio de Oria respondió a varios aspectos: la existencia de una ingente y diversa arquitectura construida en tierra (militar, religiosa, hidráulica, civil y doméstica), el estado de conservación y las medidas de intervención en la misma, la disponibilidad que el ayuntamiento ofrecía y la constatación de una actitud activa de su población en respuesta a cualquier propuesta de carácter cultural. 


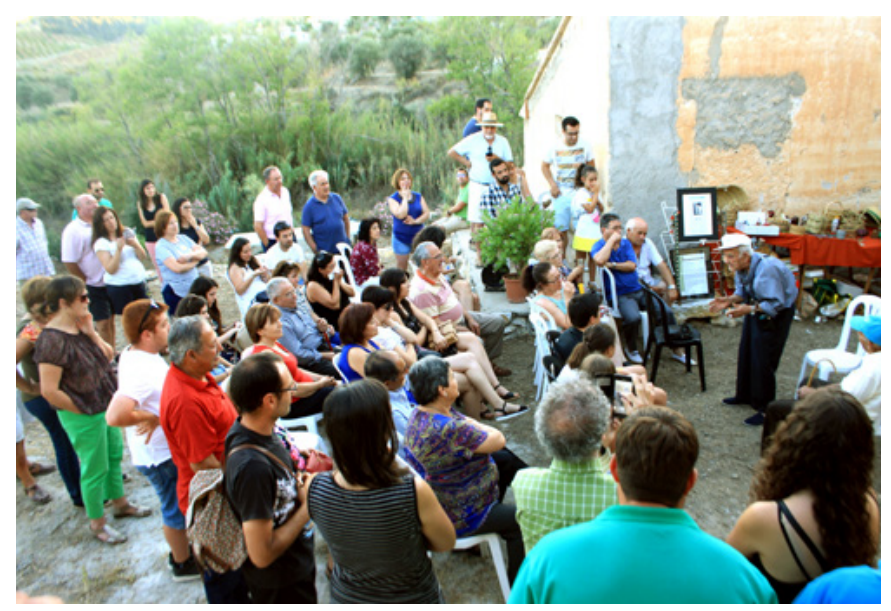

Demostración y exposición de trabajos de esparto de Evaristo Egea en el edificio de las Mazas de esparto de Oria

El éxito de la aplicación metodológica planteada como trabajo de dinamización del patrimonio conllevaba implicar de forma activa a un colectivo lo más plural posible (diversas edades, géneros, profesiones, etc.) en torno a un conjunto de acciones culturales con carácter participativo enmarcadas en unas jornadas patrimoniales. De esta forma, cada persona podría experimentar y compartir la problemática bajo una óptica plural.

La estructuración de las jornadas se articula conforme a una temática (la casa y el agua en estas dos primeras ediciones) en torno a tres acciones principales: charlas a cargo de personas investigadoras de diversas disciplinas (antropología, arquitectura, arqueología, etc.) incidiendo no solamente en sus aspectos arquitectónicos, sino también en sus usos, funcionalidades y profesiones asociadas; talleres prácticos adaptados a diferentes edades sobre técnicas constructivas tradicionales con el apoyo de antiguos alarifes y de artesanía relacionada con el uso de algunas edificaciones, donde se incide en el presente y futuro de las mismas; e itinerarios culturales donde se produce un intercambio de posturas en torno a diferentes ejemplos de arquitectura tradicional.

Estas acciones son complementadas con otras actividades trasversales que facilitan la aproximación a las jornadas a un público a priori menos interesado, a partir de exposiciones fotográficas, de pintura, presentación de revistas locales, recitales poéticos, conciertos o

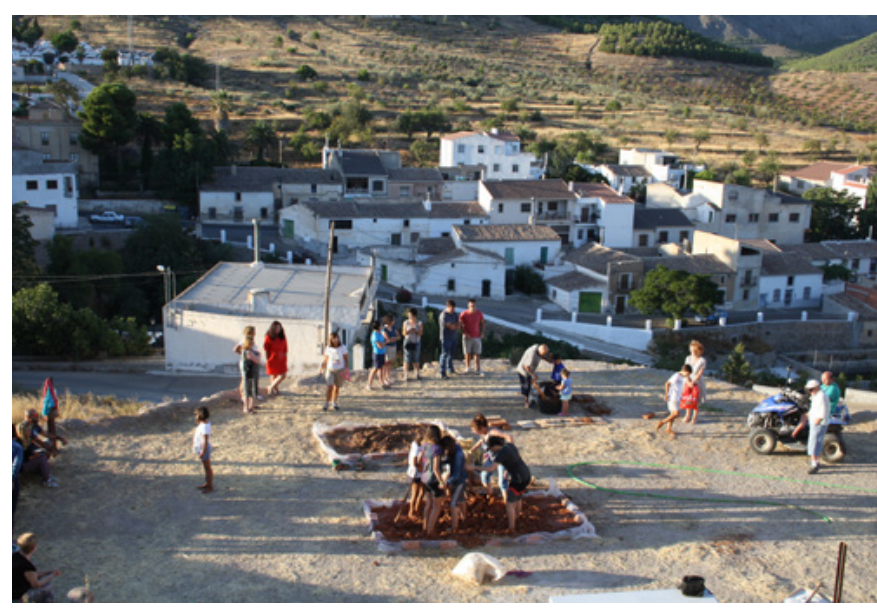

Taller de adobe en la antigua Era de Ciezar en el municipio de Oria | fotos Ginés Reche Reche

comidas vecinales localizadas en enclaves estratégicos que focalizan la problemática hacia un elemento concreto de la temática tratada. Estas interacciones culturales permiten experimentar el patrimonio colectivamente y reflexionar sobre el conjunto de valores asociados a estas arquitecturas.

El resultado de las dos ediciones celebradas hasta la fecha se muestra alentador, no solamente por la aceptación de las jornadas, sino por lo que se deriva de las mismas, donde que cada vez más se asume la arquitectura tradicional construida en tierra como un elemento identitario del pueblo que es necesario salvaguardar y que representa una alternativa sostenible (económica, ecológica y social) frente a otros tipos de técnicas y materiales. Prueba de ello es que se empieza a apostar cada vez más por la rehabilitación responsable así como la incorporación a petición de promotores y profesionales de materiales naturales en la construcción. Estos resultados suponen una motivación añadida para la continuación de las jornadas en los próximos años con la convicción reforzada de que es necesaria una actitud activa en la educación patrimonial.

\section{NOTA}

1. Becario FPI. HAR2016-78113-R. Ministerio de Ciencia, Innovación y Universidades. Fondo Social Europeo. 